\title{
The political \\ potential of numbers: data visualisation in the abortion debate
}

\section{By Rosemary Lucy HiLl}

\section{Abstract}

Data visualisation has been argued to have the power to 'change the world', implicitly for the better, but when it comes to abortion, both sides make moral claims to 'good'. Visualisation conventions of clean lines and shapes simplify data, lending them a rhetoric of neutrality, as if the data is the whole story. It is imperative, therefore, to examine how data visualisations are used to shape women's lives. This article draws on the findings of the Persuasive Data project . Google Image Scraper was used to locate abortion-related visualisations circulating online. The images, their web locations, and data use were social semiotically analysed to understand their visual rhetoric and political use. Anti-abortion groups are more likely to use data visualisation than pro-choice groups, thereby simplifying the issue and mobilising the rhetoric of neutrality. I argue that data visualisations are being used as a hindrance to women's access to abortion, and that the critique of such visualisations needs to come from feminists. This article extends discussions of how data is often reified as objective, by showing how the rhetoric of objectivity within data visualisation conventions is harnessed to do work in the world that is potentially very damaging to women's rights.

\section{KEYWORDS}

Abortion, data activism, data visualisation, feminism, pro-choice

Rosemary Lucy Hill is Lecturer in Sociology at the School of Sociology and Social Policy, University of Leeds, UK. Her research focuses on gender, big data visualisations and popular music. 


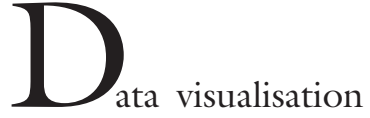

has been argued to have the power to 'change the world' (Kosara, Cohen, Cukier \& Wattenberg 2009), implicitly for the better, because it is supposed that more data can make decisions more rational (Dur 2014). But when it comes to abortion, both sides make moral claims to 'good'. Analysing data visualisations from a feminist perspective can provide a nuanced check to these overly-utopic claims and deepen our understanding of the work that the form of data visualisation does in the world. Visualisations are made by different people for different reasons, their motives may not always be 'good' or their skills up to task of being honest to the data. Indeed visualising data may provide an opportunity to "lie" (Huff 1954). With regards abortion, visualisations therefore have the power to change the world for the good, by persuading people of the need to retain or extend access to healthcare, or for the worse, by persuading people to limit access to care. Yet little is known about the persuasive power of visualisations.

This article draws on the findings of the Persuasive Data project, in which visualisations relating to abortion were located online and analysed to understand their visual rhetoric and political use. I argue that visualisations are being used as a hindrance to women's access to abortion, and that critique of such visualisations needs to come from feminists. This article extends discussions of how data is reified as objective, by showing how the rhetoric of objectivity is being harnessed to do work that is potentially very damaging to women's rights. I begin with a discussion of the literature of the power of data visualisations and of the use of visuals in abortion campaigning. I sketch out my methodology before outlining where data abortion-related visualisations can be found online and what their siting means. I then closely examine a small number of examples to highlight the ways in which the complexity of the question of abortion gets lost in the turn to data. Finally I assess what the critiques of poorly used data visualisation mean for feminist campaigning.

In popular discourse data visualisations are often portrayed as providing transparent 'windows onto data' (Kennedy, Hill, Aiello \& Allen 2016: 716). Increasingly, however, attention is being paid to the rhetorical work done by conventions in the design of data visualisations, as well as the impact of myriad subjective decisions made by designers (Bowie \& Reyburn 2014; Kennedy et al. 2016). This builds on the acknowledgement that data is never 'raw', but is produced within specific networks of people and technologies (Bowker 2005). Furthermore, the notion of viewers as rational readers, which underpins ideas about visualisations' world-changing potential, have been overstated: engaging with visualisations is bound up with emotional responses, deeply held beliefs and dependent on a range of factors (Kennedy, Hill, Allen \& Kirk 2016; Kennedy \& Hill accepted). Little is known about the persuasive powers of data visualisation, but Pandey et al. (2014) found that visually represented data is generally more persuasive than data in tabular form. This is not due to the aesthetics of the charts, rather it is the fact of seeing the data in graphical form. The ability of data visualisations to change the world can be attributed to the fact of the visual form of data, suggesting that any old data can be shoved in a graph and it will have some persuasive effect. What, then, should we make of data visualisations that are badly done, misleading, or give only a partial view of a complex issue?

Mainstream arguments about abortion tend to centre on the issue of foetal personhood. This high profile focus means that women's complex experiences of abortion, 
pregnancy, motherhood and bodily integrity are often overlooked (Cannold 2000). It is in this context that academic attention on abortion campaigning has focused on the use of visuals by anti-abortion organisations: powerfully affective photographs of babies, foetuses (Hopkins, Zeedyk \& Raitt 2005 ) or sonogram images (Palmer 2009). Palmer (2009) argues that sonograms have proven highly emotive and powerful tools for anti-abortion campaigners, in part because seeing the image is confused with knowing the foetus. This 'knowledge' is then used to further the aim of reducing the abortion time limit. Yet those expert in interpreting sonogram images acknowledge their 'beauty' and emotional power, but contest their ability to tell a truth. They argue that the emotion is in the viewer, not the foetus, and that sonogram images do not produce scientific knowledge in themselves (Palmer 2009). Increasingly data visualisations are being used by campaigning groups to tell 'truths' about abortion. This move further abstracts both the woman and the foetus and provides a new layer of perceived objectivity. Such a move could be argued to be a step away from the emotionally arresting images previously used by campaigning groups, however to see visualisations as only rational, neutral artefacts is to misunderstand the rhetorical work that they do.

\section{METHODOLOGY}

In order to understand how visualisations relating to abortion are being used by campaigning groups, I employ digital methods and social semiotic analysis. The University of Amsterdam's Google Image Scraper was used to search for visualisations. Using Google Image Search to discover data visualisations about abortion is likely to be a common method in which people search for visual data about abortion, for example school and college students seeking for images for use in educational projects. It can therefore be viewed as a valuable tool for groups wanting to change young minds about the rectitude of abortion. Since the term 'data visualisation' is most likely to be used by data specialists, it was necessary to also use more everyday alternatives: 'abortion chart' and 'abortion graph' were therefore used as search terms alongside 'abortion data visuali*ation'. History was cleared before searching and the search timeframe was set to 'any'. The three terms provided slightly different images, with the first more likely to include maps. Google Image Scraper queries Google Image Search and has the advantage of providing web addresses in an easily readable format, enabling the websites themselves to be a site of research. Using Google Image Search is a way to immediately see where images are being used (as opposed to a Google Web search, which shows text in the results) and therefore functions as a filter to show only those pages where visualisations appear. It also functions as a sampler, providing a glimpse of the kinds of visualisations online and the kinds of sites on which they appear. Using Google Image Scraper is therefore an effective way of querying the web to find out where and how data visualisations are being used by campaigning groups.

This approach is also revealing of Google Image Search's representation of abortion through data. Rogers (2015) argues that we need to think of Google as a research tool in a way that is distinct from our everyday usage of it; we need to be critical of the results it provides. Google uses digital objects to rank and index pages, placing those that are most linked to at the top of the search results. There are a number of other factors in the return of pages (e.g. location of the user, the reputation of the site, removal of duplicate pages, trending pages, past user behaviour), so Google does not straightforwardly present the most popular or most relevant search results. Rogers argues that Google's search results 
are a good indication of what the dominant story about a search topic is (Rogers 2009), but this does not mean that the results are uncontroversial or politically neutral (Cadwalladr 2016). Indeed, Introna and Nissenbaum (2000) caution that market forces play a significant role in which pages are returned, and this runs counter to the ideals of a free and democratic web as originally envisioned. Therefore the distance from the top of Google Image Search's page results says something about both what the dominant story about abortion is, and how Google presents it within a politically charged context. Nevertheless, this article is primarily concerned with the representation of abortion through data visualisations on campaigning websites, rather than through Google's representation of abortion per se.

Focusing on the top 20 search results in each search, I undertook semiotic analysis of visualisations to investigate the rhetorical devices being used. These 60 search results are just a snapshot of abortion-related visualisations, but a snapshot that has meaning when we acknowledge that few people look beyond a first page of search results. These are the kinds of visualisations that will typically by found and viewed. Social semiotics draws attention to the text and considers the ideology that can be identified within. It is a valuable method for gathering the analyses and tools for social change (Aiello 2006). The approach means breaking down the visualisations into individual elements and assessing how these elements make meanings. It also requires attention to the context of the visualisations, and so I include here close readings of the webpages on which visualisations appear. Here I build on research that identifies the conventions (Kennedy, Hill, Aiello \& Allen 2016) and rhetorical devices (Hullman \& Diakopoulos 2011) of data visualisations.

\section{A LACK OF PRO-CHOICE VISUALISATIONS}

Google Image Scraper brought up data visualisations primarily from the US. They appear on news sites, personal blogs, visualisation specialist sites, and campaigning sites, amongst others. The majority of sites offer neutral perspectives on abortion (16 of 34 sites), followed by anti-abortion (ten) and pro-choice (seven). Table 1 shows a breakdown of the sites by type, position and number of visualisations.

Out of the 60 visualisations, 28 are on anti-abortion websites, five on visualisation critique sites, and only nine on pro-choice sites. Pro-choice visualisations appear on personal blogs (two) and campaign sites (two), but two also appear in a journal article in the UCLA Law Review. Abortion-related visualisations appear on data and visualisation sites such as graphs.net, where they are offered without comment, and vislies.org, where they are the subject of critique. News sites tend to present a neutral portrayal of abortion, although not always (e.g. The Economist uses a visualisation in an anti-abortion article). Of the campaigning sites, most are anti-abortion, with one anti-abortion site providing the majority of the visualisations (Live Action with six visualisations). Overall, the majority of antiabortion visualisations in the data set (14) are hosted by ClinicQuotes. ClinicQuotes is the personal blog of Sarah Terzo, who also writes for Live Action. The visualisations appear on a page entitled 'Abortion Visual Aids, Graphs and Charts' with very little explanatory text. Reprint permissions indicate that the author wishes their visualisations to be used elsewhere, which suggests that visualisations will be taken from this website as if their context does not matter, as if the data can speak for themselves.

What is significant about the visualisations from campaigning sites in these findings is that Google presents US anti-abortion visualisations first, and there are significantly more of them. Furthermore, anti- 
TABLE 1: BREAKDOWN OF SITES BY TYPE, LOCATION AND POSITION ON ABORTION, INCLUDING NUMBER OF VISUALISATIONS APPEARING IN THE SEARCH RESULTS

website

Euthanasia.Com

Feministing

Live Action

Pelican Parts

Padjo

Patfagan

Science Leadership

Politifact

Our Bodies Ourselves

UCLA Law Review

BBC

Economist

Humanosphere

Journalists Resource

New York Times

Talking Points

The Blaze

Think Progress

Washington Post

Abortion Rights

For Women

Bay of Fundie

ClinicQuotes

DarwinCatholic

Gatech

Jill Stanek

Johnstonsarchive

Nathan Cherry

Rampages

Peltiertech

Ranking America

Graphs.net

Pinterest Explore

School of Data

Vis Lies $\begin{array}{ll}\text { no. visualisations } & \text { type of } \\ \text { in search results } & \text { website }\end{array}$

campaign
campaign
campaign
car parts forum
education
education
education
fact checking
health
journal

news

news

1 (irrelevant)

1

1

1

1

1

2

1

1

14

1

1

1

4

I

I

1

1

2

1

1

1

visualisation

visualisation location
of website

US

US

US

US

US

US

US

US

US

US

UK

UK

US

US

US

US

US

US

US

US

US

US

US

US

US

US

US

US

US

US

US

US

Macedonia

US position on abortion

anti-abortion

pro-choice

anti-abortion

neutral

neutral

anti-abortion

anti-abortion

neutral

pro-choice

pro-choice

neutral

anti-abortion

neutral

neutral

neutral

anti-abortion

pro-choice

neutral

pro-choice

pro-choice

anti-abortion

anti-abortion

neutral

anti-abortion

neutral

anti-abortion

neutral

neutral

neutral

neutral

neutral pro-choice

neutral 
abortion groups use more data visualisations than pro-choice groups, and there is a difference in the kinds of visualisations being used. Anti-abortion groups tend to use polling figures relating to opinions on abortion, statistics on numbers of abortions, who has them at which point in their lives and at which point in their pregnancies. Feministing, the only pro-choice campaign group in the sample, presents charts relating to threats against abortion providers and restrictions on abortions in different states. Our Bodies Ourselves, a women's health website, presents data on misinformation in state mandated documents given to women seeking terminations, and a UCLA Law Review article presents visualisations about women's fertility choices over their lifetimes. These offer a different perspective from the anti-abortion statistics. These varying viewpoints reflect the complexity of the debate on abortion in the US, but it is significant that visualisations which relate specifically to figures on the process of abortion are being prioritised in Google Image Search. It raises a further issue of how quite minimal visualisations are being used, stripping the issue of other contextual matters.

\section{THE MISSING CONTEXTS OF DATA CREATION AND WOMEN'S EXPERIENCES}

One of the major issues with the use of data visualisations by anti-choice bloggers, is the use of data with very little context. Minimalist visualisations enable the writer to create the narrative into which the visualisation fits. The data therefore become the 'facts' of the matter, even though there is only limited information available. This relates to both the context of data creation, and to the context of abortion in the US.

It is a typical visualisation convention to acknowledge the source of the data, thereby giving the visualisation the appearance of transparency. However, few people actually have the skills to be able to interpret the data if they do take the time to go back to them (Kennedy, Hill, Aiello \& Allen 2016). When it comes to the visualisations provided by ClinicQuotes and Live Action, data sources are in evidence but there is typically a lack of information about how the data have been generated. The data are coming from elsewhere such as Gallup and Guttmacher, organisations who have credibility, and so including these sources lends authority to the graphs. However, this suggests that American readers are expected to know how these organisations create their datasets, which may not be the case. This problem is particularly apparent in ClinicQuotes' visualisation 'Most Americans say they don't know enough about the abortion pill to say if it is safe and effective' (See Figure 1).

The visualisation contains two $3 \mathrm{D}$ pie charts which show responses to polling about people's feelings about the abortioninducing medication mifepristone. The largest segment of both charts is 'don't know'. The main message of the visualisation is therefore that people do not know what to think about mifepristone; they feel ill-informed. This implies that people ought to be well informed because, it is intimated, there are safety concerns about the drug. It should be noted that mifepristone is approved by the FDA and is regarded as 95\% effective. There is no further information about the data creation process, or about mifepristone. This visualisation (as with the others on ClinicQuotes) is therefore presented as the facts of the matter, as if it is telling a full story. However, how much are the general population likely to know about the safety and efficacy of any drug? Who was polled? Why ask ordinary people's opinions about the drug? It is likely that the only people qualified to make judgements on the topic are those who are medically trained to evaluate the evidence. Yet the visualisation notes only that 'Americans' were polled. If the organisation were aiming for a representative sample then 


\section{FIGURE 1:}

MOST AMERICANS SAY THEY DON'T KNOW ENOUGH ABOUT THE ABORTION PILL TO SAY IF IT IS SAFE

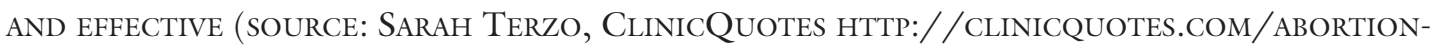
VISUAL-AIDS-GRAPHS-AND-CHARTS/)

From what you know, how safe is Mifepristone or RU-486 when used under a doctor's care for medical abortion -- is it very safe, somewhat safe, not too safe, not at all safe, or don't you know enough about this issue to answer?

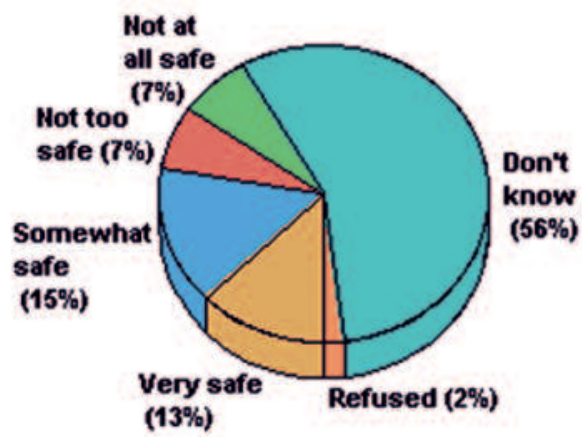

Source: Kaiser Family Foundation $8 / 01$

\begin{abstract}
From what you know, how effective is Mifepristone or RU-486 when used under a doctor's care for medical abortion - - is it very effective, somewhat effective, not too effective, not at all effective, or dont you know enough about this issue to answer?
\end{abstract}

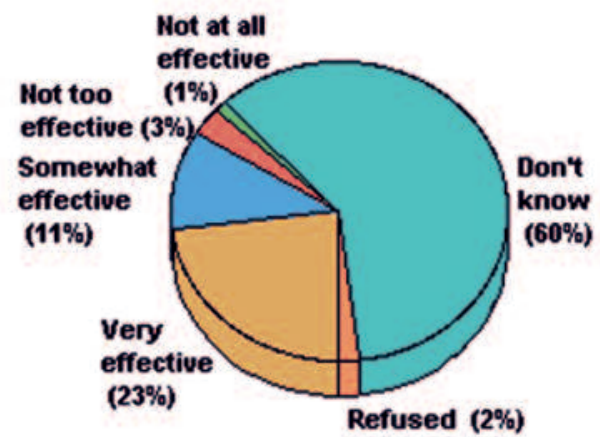

Sounce: Kaiser Family Foundation 8.01

Figure 2:

Abortion Rate \& Ratio vs Poverty Rate (source Darwin, DarwinCatholic http://DarWINCATHOLIC.BLOGSPOT.CO.UK/2008/03/POVERTY-AND-ABORTION-NEW-ANALYSIS.HTML)

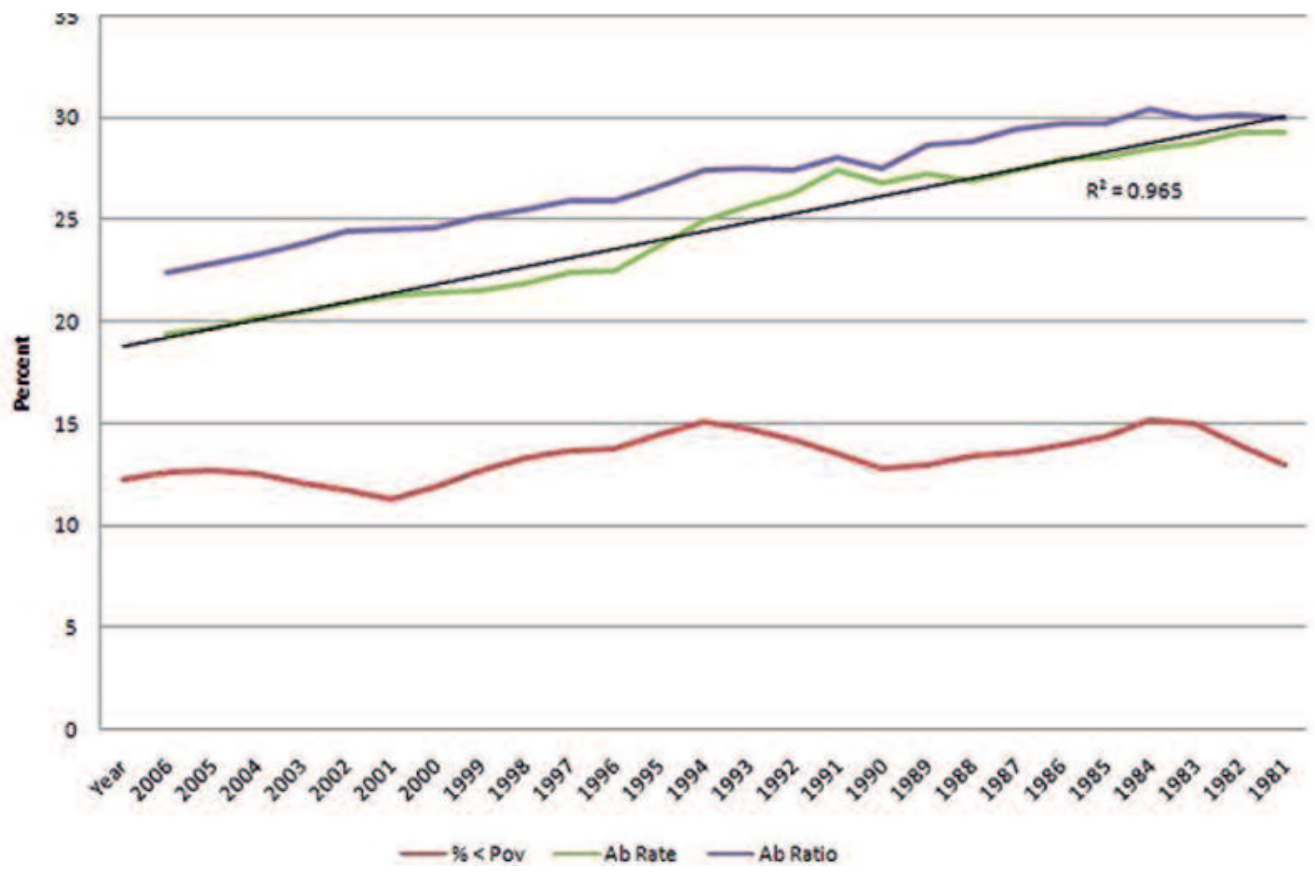


around half of those polled would be men and a number of the women would be post-menopausal, sterilised, infertile, using long-term contraception or not in heterosexual relationships (Goldstein 2010). That is, many people polled are unlikely to have much awareness of mifespristone because they have no need to know. It therefore should not be surprising that more than half the sample answered 'don't know'. Whilst ordinary people's opinion is visualised as if it is valuable, it says little about the actual safety or effectiveness of the drug. These polling data should not be taken as indicating that it is a problem that people know little about mifespristone.

A further issue with the anti-abortion visualisations is the lack of context about what abortion means in women's lives. This is consistent with a foetus-centred narrative of the meaning of abortion in antiabortion campaigning, although not all visualisations relate to foetuses. 'Abortion Rate \& Ratio vs Poverty Rate' (Figure 2), which appears on the personal blog DarwinCatholic, is a good example of how a focus on particular statistics removes the context of abortion in women's lives, with the effect of making the visualisation itself difficult to understand.

The visualisation asks the viewer to understand for themselves - to see and know that there is no correlation between abortion and poverty, and to view this data as the facts of the matter. DarwinCatholic is anti-abortion and seeks to bring a scientific examination of data to religious discussions. The article uses the language of statistics, although the timeline on this graph runs backwards which undermines the author's authority when it comes to statistical literacy. Neither the visualisation nor the article discuss why women have abortions, access to contraception or what it means to be a mother on the breadline, i.e. what the actual relationship between poverty and abortion might be. Both poverty and abortion are taken out of the context of women's lives and decision making about their families. The visualisation therefore gives a sense of rationality and contributing to informed debate, although there is very little information here. The wider purpose of the article is to argue that abortions in the US are falling of their own accord, a natural shift after the unnatural high of the federal legalisation in 1973. Darwin does not take into account that $r e^{-}$ porting of abortions would have increased post-1973, since abortion was no longer criminalised. Darwin also claims that the fall in numbers of abortions is due to

\section{(...) a build-up of painful experience, which} has overcome the initial impression that the costs of getting pregnant (and getting out of getting pregnant) are not as high as they were before 1973 (Darwin 2008).

He has no evidence for this claim. Indeed, it is disputed by the UK Royal College of Obstetricians and Gynaecologists (2016), who found that continuing an unwanted pregnancy has a more detrimental impact on women than terminating one. To conclude a blog post which purports to be factual with an unsubstantiated (and untrue) claim, further undermines the author's position as an authority, in spite of that which is lent by the use of statistics and graphs.

In the sense of providing context about women's lives, a much better visualisation is 'Women's Reproductive Choices by Age with Estimated Abortions' (see Figure 3), which appears in an article in the UCLA Law review.

Goldstein considers women's management of their reproductive health and lives as a "human procreative project" (2010: $5)$. The article is not a campaigning article, but it uses the data and the visualisation to make a pro-choice argument: that women's judgements about family planning are "informed and entitled to the respect owed to those who know something of life" (2010: $12)$. In this visualisation and the accompa- 
nying narrative, abortion is considered in the context of women's lives and choices about the children they do not have, may have or already have.

\section{DATA VISUALISATION CRITIQUES AND THE QUIET FEMINIST VOICE}

A further noteworthy type of site on which data visualisations are published is sites specialising in discussion of data visualisation as a form. In some cases (e.g. graphs.net and Pinterest's data visualisation examples page) a variety of visualisations are presented uncritically. School of Data, Vis Lies 2015 and Politifact, however, all offer apparently disinterested critiques of poorly executed visualisations.

One of the visualisations comes from School of Data, a Macedonian site that reprints blog posts about the use of data for advocacy ends. The post, by Mushon Zer-Aviv, looks at a number of different visualisations relating to abortion and offers critical examination of their flaws. The author is pro-choice, but the visualisations are from both sides of the debate, so he presents himself as a disinterested data visualisation specialist, rather than a campaigner. Zer-Aviv's discussion is incorporated into the Public Affairs Data Journalism at Stanford University module page (http:// www.padjo.org/2014-11-20/) and also into the Vis Lies 2015 academic discussion of poor visualisations (http://www.vislies. org/2015/gallery/), and visualisations from these page do appear in my dataset. Zer-Aviv's criticism of poor abortion-related data visualisations is therefore the dominant voice in criticisms of the anti-abortion use of data. The criticisms are not only that data is being poorly visualised, but that it is being visualised in such ways that it misleads the viewer.

Zer-Aviv discusses the visualisation 'Abortion in the United States' (see Figure 4) by the now defunct anti-abortion campaign group Live Citizen. The visualisation shows statistics about abortion rates worldwide and in the US. Zer-Aviv argues that: the amount of information on the page makes for an overwhelming visualisation; the portrayal of race and abortion neglects to discuss the relationship between race and wealth (although he does not actually provide any evidence of a relationship between poverty and abortion); the change of scales between worldwide and US figures appear to overstate the US's abortion figures; the social reasons reduce the original information provided in the data. What Zer-Aviv does not overtly do is criticise the emotionally manipulative approach to displaying the data. He keeps his attention on the way in which the data is being misused, taking a rational approach.

So how does this emotional manipulation work to create a very powerful visualisation, in spite of its careless approach to data? The visualisation uses metaphors in which the birth rate is equated with mothering and nursing newborns (women holding babies, prams), and the abortion rate is equated with women discarding newborn babies into dustbins. Blue and pink icons divide the population into equal parts male and female, using the common convention of gendered colour associations. In doing so the visualisation makes use of some common discourses: the gender binary is natural; babies are nursed by women; women are in charge of birth rates and abortion rates; abortion is casually done. This makes for a moralising tone by reifying women as mothers and demonising those who terminate a pregnancy as baby killers. Of course most terminations happen within the first three months of pregnancy when the foetus is not baby-like and could not survive outside the womb. The equation of the foetus with a baby is a common slippage that occurs in anti-abortion campaigning (Daniels, Ferguson, Howard \& Roberti 2016), but this is not one of the critiques made by Zer-Aviv.

The critiques of misinformation in anti- 


\section{Figure 3:}

Women's Reproductive Choices by Age with Estimated Abortions (Source Robert D. GOLDSTEIN HTTP://WWW.UCLALAWREVIEW.ORG/PICTURING-THE-LIFE-COURSE-OF-PROCREATIVE$\mathrm{CHOICE} /$ )

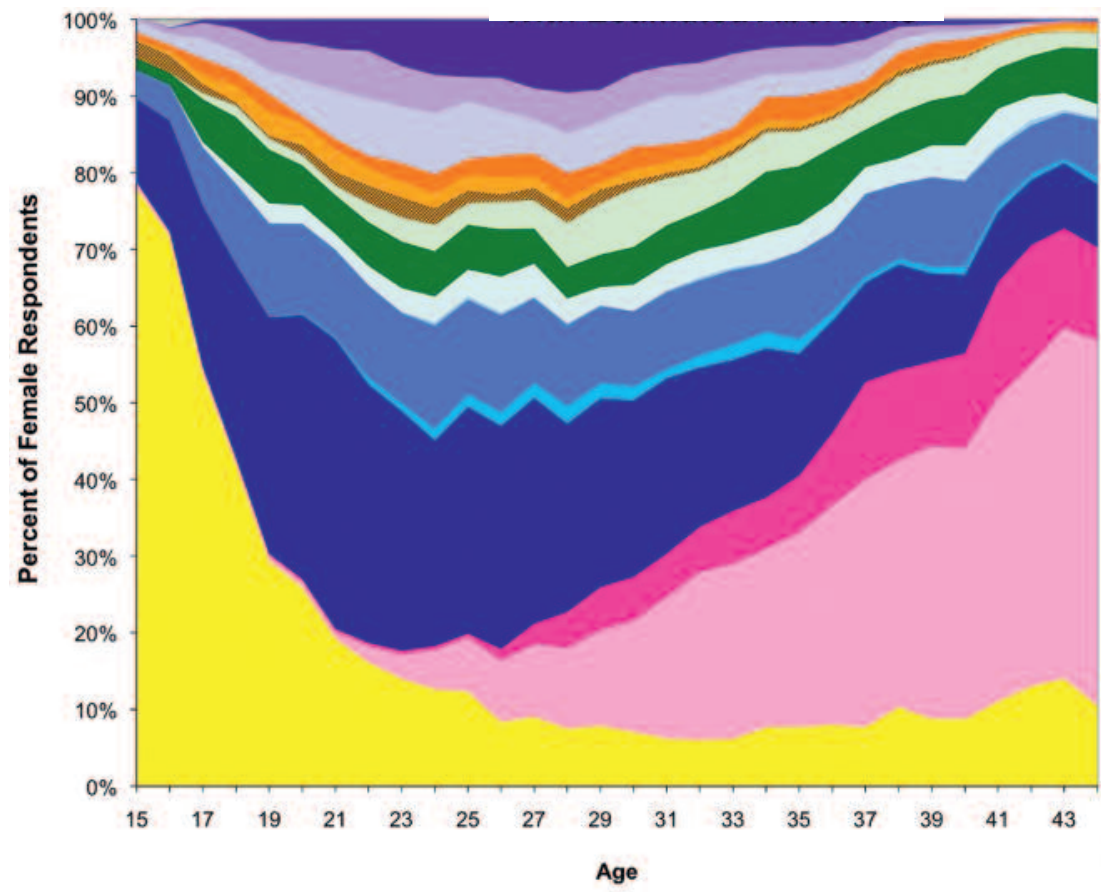

- Had a planned live birth
" Had an unplanned live birth
Currently pregnant
"Had a miscarriage
"Had an abortion
"Estimated unreported abortions
Wishes to become pregnant
-Sexually active not contracepting
Using other method of
contraception
"Using diaphragm, sponge, or
cervical cap
"Using condoms
" Using hormonal contraception
" Male sterilization
" Female sterilization

abortion visualisations and data use come primarily from visualisation specialists adapting or reprinting Zer-Aviv's work. They take a rational approach to criticising poor or misleading data use and visualisation. They present themselves as neutral, objectively turning their critical eyes on both anti-abortion and pro-choice visualisations. They are therefore not critical of the ways in which such misinformation or half-truths are being used as specific campaigning tools with the aim of limiting women's access to healthcare. There has so far been little criticism from feminist organisations. In these search results feminist groups have used visualisations to provide other perspectives on abortion rather than attempting to counter the misinformation spread through anti-abortion visualisations.

Why might this be? I posit that the split into separate, gendered camps of science, technology and quantitative methods on the one hand and arts, social sciences and qualitative methods on the other has an unlucky part to play. Feminist research in the social sciences has primarily utilised qualitative methods, with some degree of suspicion for quantitative methods (Scott 2010). This means that there is a gender skills gap in working with data (Cohen 2016) and undertaking visualisation work. It accounts for a lack of understanding of data which translates into fewer critiques of visualisations. When it comes to producing visualisations - and note that the majority of the visualisations in the sample are from anti- 


\section{Figure 4:}

Abortion in the United States (Source Live Citizen, htTP://schoolofdata.metamorPHOSIS.ORG.MK/CATEGORY/DATA-JOURNALISM/PAGE/3/)

\section{Abortion in the United States}

\section{$\checkmark$ WORLDWIDE}

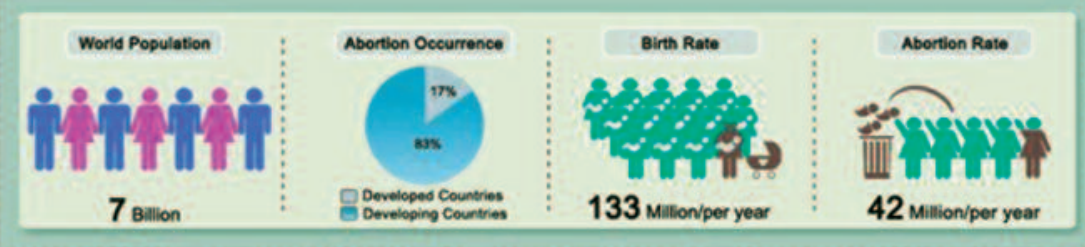

\section{- UNITED STATES}
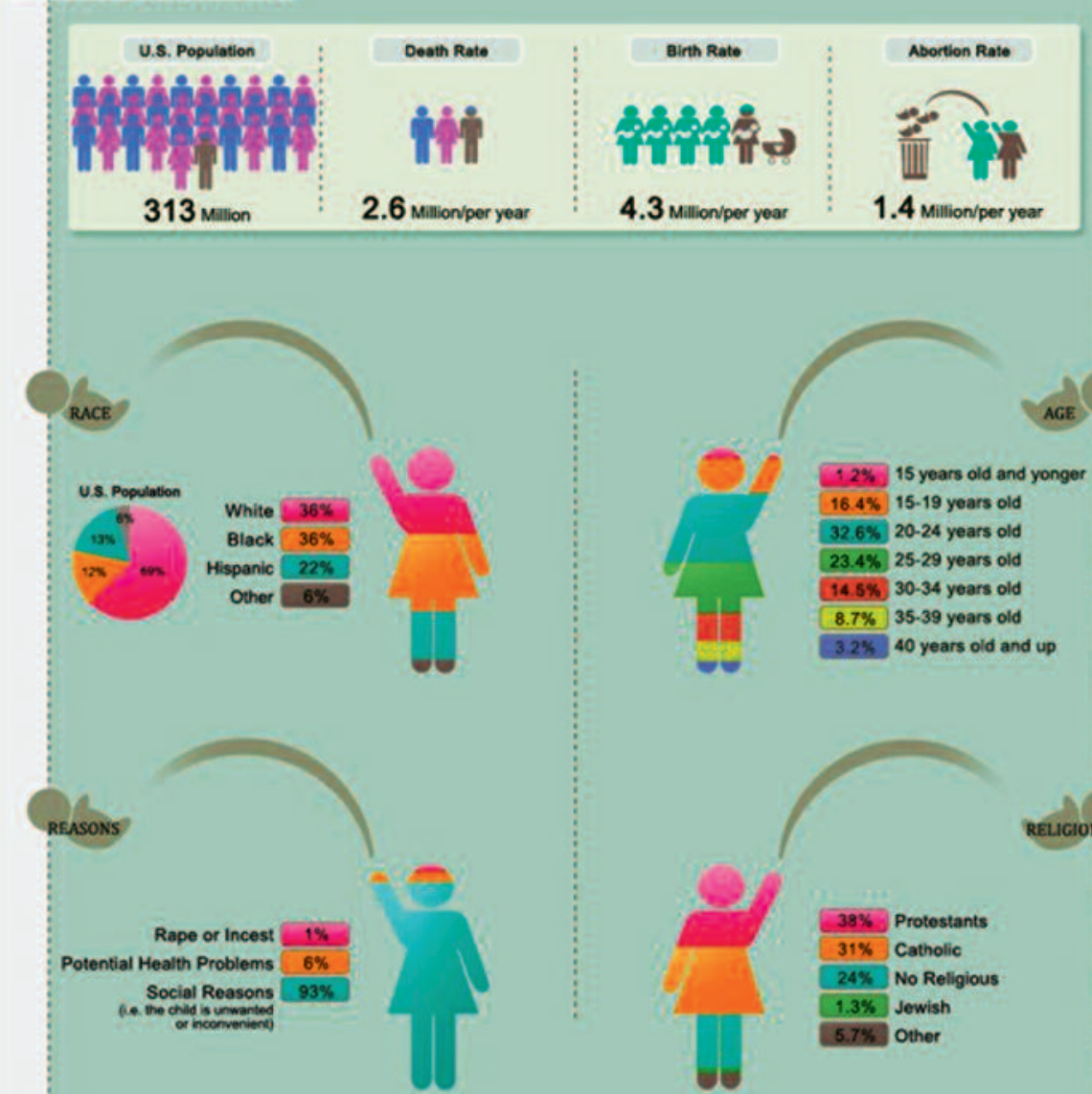
abortion groups - this skills gap will also contribute to a lower proportion of prochoice visualisations. But it may be that pro-choice research and perspectives do not lend themselves well to data visualisation when the emphasis is on the quantitative. Abortion is a complex issue and it has been too often reduced to simple statistics which do not capture important factors like how abortion fits into women's lives. As D'Ignazio and Klein (2016) argue, taking a specifically feminist approach to visualising data is an important means through which to develop more inclusive and less reductive data representations.

\section{CONCLUSION}

Using Google Image Search to find data visualisations about abortion reveals a lack of pro-choice visualisations from campaigning sites, with US anti-abortion campaigning visuals much more prominent. This means US anti-abortion groups, already internationally powerful, are positioned as providing important data on abortion. Moreover, such data visualisations often strip context from the issue being visualised, which is a much wider problem of data visualisation in general: visualisers need to do significant work to make contexts of data production and visualisation creation clear, and here this work has not been done. It is also the case that information regarding the role of abortion in women's lives is left out of the discussion. The result is that foetus-centred narratives continue to dominate and to appear as if they tell the whole story: women's perspectives are minimised. We know that data is often viewed as objective, carrying the status of 'facts' about the world. Because of this rhetorical dimension, data visualisations can hold a power to persuade people to particular viewpoints which can be mobilised for political ends. In this case, then, far from changing the world for the better, data visualisations are potentially damaging women's rights through provid- ing mis- or partial information or tell damaging stories about women (e.g. that motherhood is our natural role). Context, especially when it comes to complex concerns, is therefore crucial.

In critiquing anti-abortion visualisations that seek to mobilise data in order to reduce women's access to healthcare, the broader perspective of abortion in women's lives needs to be taken into account. The critiques made by visualisers which focus only on poor uses of data therefore miss out on this vitally important piece of the discussion. It also speaks of feminists' lack of skills when it comes to working with quantitative data, but highlights how vital it is that women's rights campaigners are able to do this (Hill, Kennedy \& Gerrard 2016). Organisations such as Feministing are doing good work in telling different stories about abortion; pro-choice campaigners need to build on this to put women in the data picture, to utilise the persuasive potential of numbers even in light of the difficulty of visualising such a complex topic.

The case of abortion shows how claims that data visualisation can 'change the world' (Kosara, Cohen, Cukier \& Wattenberg 2009) risk ignoring a diverse range of perspectives on what counts as a better world. The idea that visualisations can provide enough information upon which to base decisions is in itself idealistic. Data visualisations necessarily simplify (Manovich 2011) and this means that the majority of visualisations do not provide enough detail or context to enable people to be really informed. Examining data visualisation from a feminist perspective therefore enables these problems with the form of and claims for data visualisation to be made visible, as well as offering insights into the uses of visualisations by campaigning groups for hindering or promoting women's access to healthcare. 


\section{Note}

1. Persuasive Data is a small scale research project conducted by the author. For more information see: http://seeingdata.org/persuasive-data/

\section{REFERENCES}

- Aiello, Giorgia (2006): Theoretical advances in critical visual analysis: perception, ideology, mythologies, and social semiotics, in: Journal of Visual Literacy 2006/26(2): 89-102.

- Bowie, Anneli \& Reyburn, Duncan (2014): Expanding the Terministic Screen: A Burkean Critique of Information Visualization in the Context of Design Education, in: KB Journal 2014/10(1). - Bowker, Geoffrey C. (2005): Memory practices in the sciences. MIT, London.

- Cadwalladr, Carole (2016): Google is not 'just' a platform. It frames, shapes and distorts how we see the world. The Guardian. 11/12/2016. On https://www.theguardian.com/commentisfree/2 $016 / \mathrm{dec} / 11 /$ google-frames-shapes-and-distortshow-we-see-world.

- Cannold, Leslie (2000): The abortion myth: Feminism, morality, and the hard choices women make.

Wesleyan University Press, Middletown.

- Cohen, Rachel Lara (2016): Towards a quantitative feminist sociology, in: Linda McKie \& Louise Ryan (eds.): An end to the crisis of empirical sociology? Trends and challenges in social research.

Routledge, Abingdon.

- D'Ignazio, Catherine \& Klein, Lauren F. (2016): Feminist data visualization, in: IEEE VIS. 2016. - Daniels, Cynthia R.; Ferguson, Janna; Howard, Grace \& Roberti, Amanda (2016): Informed or misinformed consent? Abortion policy in the United States, in: Journal of Health Politics, Policy and Law 2016/41(2): 181-209.

- Darwin (2008): Poverty and abortion: a new analysis DarwinCatholic: where religion, philosophy and demographics meet. 06/03/2008. Available at: http://darwincatholic.blogspot.co.uk/2008/03/ poverty-and-abortion-new-analysis.html.

- Dur, BanuInanc Uyan (2014): Data visualization and infographics in visual communication design education at the age of information, in: Journal of Arts and Humanities (JAH) 2014/3(5): 39-50. - Goldstein, Robert D. (2010): Picturing the life course of procreative choice, in: UCLA Law Review 2010/58(Discourse 5): 5-25.

- Hill, Rosemary Lucy; Kennedy, Helen \& Gerrard, Ysabel (2016): Visualizing junk: big data vi- sualisations and the need for feminist data studies, in: Journal of Communication Inquiry 2016/40(4): 331-350.

. Hopkins, Nick; Zeedyk, Suzanne \& Raitt, Fiona (2005): Visualising abortion: emotion discourse and fetal imagery in a contemporary abortion debate, in: Social Science \& Medicine 2005/61(2): 393-403.

- Huff, Darrell (1954): How to lie with Statistics ... Pictures by Irving Geis. Victor Gollancz, London. - Hullman, Jessica \& Diakopoulos, Nicholas (2011): Visualization rhetoric: Framing effects in narrative visualization, in: Visualization and Computer Graphics, IEEE Transactions on 2011/17(12): 2231-2240.

- Introna, Lucas D. \& Nissenbaum, Helen (2000): Shaping the web: why the politics of search engines matters in: The Information Society 2000/16(3): 169-185.

- Kennedy, Helen and Hill, Rosemary Lucy (accepted): The feeling of numbers: emotions in everyday engagements with data and their visualization, in: Sociology.

- Kennedy, Helen; Hill, Rosemary Lucy; Aiello, Giorgia \& Allen, Will (2016): The work that visualisation conventions do, in: Information, Communication \& Society 2016/19(6): 715-735.

- Kennedy, Helen; Hill, Rosemary Lucy; Allen, Will \& Kirk, Andy (2016): Engaging with data visualizations: users, socio-cultural factors and definitions of effectiveness, in: First Monday 2016/ 21(11).

- Kosara, Robert; Cohen, Sarah; Cukier, Jérôme \& Wattenberg, Martin (2009): Panel: changing the world with visualization, in: IEEE Visualization Conference Compendium, Citeseer.

- Manovich, Lev (2011): What is visualisation?, in: Visual Studies 2011/26(1): 36-49.

- Palmer, Julie (2009): Seeing and knowing: Ultrasound images in the contemporary abortion debate, in: Feminist Theory 2009/10(2): 173-189. - Pandey, Anshul Vikram; Manivannan, Anjali; Nov, Oded; Satterthwaite, Margaret \& Bertini, Enrico (2014): The persuasive power of data visualization, in: IEEE Transactions on Visualization and Computer Graphics 2014/20(12): 22112220 .

- Rogers, Richard (2009): The Googlization question, and the inculpable engine, in: K. Becker \& F. Stalder (eds.): Deep search: the politics of search engines beyond Google. Transaction, Edison, N.J.

- Rogers, Richard (2015): Digital methods for web research, in: Robert Scott \& Stephan Kosslyn (eds.): Emerging trends in the social and behavioral sciences. John Wiley \& Sons. 
- Royal College of Obstetricians and Gynaecologists (2016): Q广A: abortion and mental health. Available at:

https://www.rcog.org.uk/en/news/campaignsand-opinions/human-fertilisation-and-embryology-bill/qa-abortion-and-mental-health/.
- Scott, Jacqueline (2010): Quantitative methods and gender inequalities, in: International Journal of Social Research Methodology 2010/13(3): 223236. 